Reflecting on action: revisiting research, exploring sexuality and enhancing reflexivity.

Ian Dore,

School of Applied Social Science,

University of Brighton,

Brighton,

UK.

i.dore@brighon.ac.uk

No acknowledgements.

Ian Dore is a Senior Lecturer in social work, he is a registered Social Worker and qualified Practice Educator. 


\title{
Reflecting on action: revisiting research, exploring sexuality and enhancing reflexivity.
}

\begin{abstract}
Revisiting research from an autoethnographic perspective can yield insights into researcher subjectivity, as attempts are made to consider one's subject position and situate the whole self within the research. In this article, the researcher revisits a piece of previous research, embarking on a reflective journey which documents the learning from what became a reflexive process, informed and framed by psychosocial thinking. In exploring the subject of vulnerability, the researcher is led to interpretations of their own biography. This initially leads to an unsettled self, before culminating in a greater sense of self-awareness. In exploring a site of reflective resistance linked to the author's sexuality, the article considers issues of identity and power, attendant to the effects of social discourse in terms of hegemonic masculinity.
\end{abstract}

\section{Keywords}

Reflexivity, psychosocial, vulnerability, social work, subjectivity, sexuality.

\section{Introduction}

This article charts a reflective process that began with a conversation between a colleague and I, about possible topics I might develop as a doctoral study. The discussion focused on one of my earlier pieces of research; exploring how conversations about emotion are enabled with student social workers in supervision (Dore, 2019); causing me to reflect on what I had produced and to engage, more critically, with myself as a researcher. Utilizing a reflective process outlined by Schön (1983), I revisit the original research to retrospectively consider the subject of vulnerability, before going on to explore the biographical aspects of gender and 
sexuality, subsequently provoked as sources of potential influence on my practice. My reflections are informed by, and understood within, a psychosocial perspective - initially influenced by Schofield's (1998) conceptualisation of inner and outer worlds. Considering identity and power, I attend to the effects of social discourse in terms of masculinity (see Frosh, Phoenix and Pattman, 2003; Redman, 2005), as well as some of the more psychoanalytical readings, that may hold scope for furthering an understanding of the dynamic interplay between the self and the external world. Adopting the stance that we are psychosocial (see Hollway, 2004), my interpretations are presented as an autoethnographical account, an approach which can capture changes experienced by a researcher, as a consequence of doing research - something which is a fundamental part of reflexive ethnography (see Ellis, Adams and Bochner, 2011) - and one, therefore, able to accommodate the liminality (transitional learning) which can emerge from reflexive engagement (see Leonard and O’Connor, 2018). Like Richards (2015), whose autoethnography also reflects on personal identity, I recognise personal growth, particularly in the sense of becoming a researcher better able to locate themselves within the research (Fook, 1999).

The article opens with a contextual narrative about the reflective process undertaken, within which I identify a site of reflective resistance attached to my sexuality. This acknowledgement goes on to become the basis of subsequent analysis, where I draw on psychosocial ideas to help understand the resistance identified. Throughout the article parallels are made with social work practice, which are used to help situate what is discussed and enhance understanding.

\section{Finding the way - parallels with practice}


Prior to the aforementioned conversation, my colleague had read my recently published research which identified themes, related to the approach and actions taken by Practice Educators, that helped enable student social workers to talk about emotive practice events (Dore, 2019). From our discussion, two comments stood out: the first related to a sense that there was, potentially, more to be explored in terms of vulnerability (of the participants and their conversations about emotion) and, secondly, they felt that 'I' was not particularly visible within the work. Following this, I became enmeshed in a reflective process reminiscent of that described by Schön (1983): I initially started to think about what I had (or had not) done - reflection-on-action - and, almost simultaneously, found myself cognitively and affectively situated back within the research, generating new thoughts and actions, as I attempted to answer the 'why' questions that it had provoked - reflection-in-action.

With a focus on what is happening in the moment and having a concern for thoughts, actions and positions of knowing, reflection-in-action seeks to uncover a deeper level of understanding of behaviour, of actions and reactions. Schön describes this as a process where, as the individual tries to make sense of events, 'he also reflects on the understandings which have been implicit in his action, understandings which he surfaces, criticizes, restructures, and embodies in further action' (1983, p. 50). Reflection-in-action is thus a reflexive approach, one of self-reflective awareness (Fook, 1999), where, similar to the practitioner, the researcher too may 'observe in action', 'step back to reflect' and 'step up again to action' (Attia and Edge, 2017, p. 36). Indeed, social science research and understanding in social work is united, or arguably should be, not just by the concepts of reflection and reflexivity, but also by hermeneutic and reflective understandings of knowledge generation (Ruch, 2000). Processes of interpretation are certainly 'indispensable to social work' (Gray and Webb, 2013, p. 3), they fulfil a central role in determining how 
individuals understand and the versions of reality they come to 'know' (Dore, 2018) invariably influenced by our own world view. All sense-making takes place within a frame of reference of one kind or another and, for Schön, asking questions like 'how am I framing the problem that I am trying to solve?' (1983, p. 50) is an integral part of the reflective process.

How things are framed not only sets parameters in terms of focus, frames also guide action and influence outcomes - determining events from how individuals make ethical decisions (for example Banks, 2016), to playing a key role in how material becomes constructed by the researcher (Fook, 2002). Lenses are formed and reformed as individuals interact with the world and create understandings of it, each interaction being shaped by power, sameness or difference - subjects explored by Heron (2005), when considering how to enhance selfawareness in student social workers. She posits that our positions within society and responses to others are shaped by our own social location, as related to characteristics such as those of race, class, gender, sexuality, ability - concepts which also represent systems that are held together and exert power in a way that is 'mutually constitutive and constantly interactive' (2005, p. 347). Conscious of this, and the potential implications it may have for identity and its expression, I began to think more deeply about my own subjectivity. In my research I had acknowledged research interests and professional experience but had not gone further; the biographical characteristics (see Fook, 1999) of who I was, were not there and so became the central focus. This provoked thoughts about whether there were any unconscious influences that had caused a lacuna of some kind, calling me to question the lenses that I did, or did not, use to see. 
Interrogating my previous position and in a bid to consider my whole self in relation to the research (Fook, 1999), I moved to think about my inner and outer worlds, also contemplating, as Ruch (2000) advocates, sites of resistance within them. As such, I consciously positioned elements of my biography as interpretive windows that might offer insight, becoming engaged in a process of 'retrospective reflexivity' (Attia and Edge, 2017, p. 35) where the effects of the research came into view, manifesting as a shift in how I thought about myself in relation to my role as a researcher. In reflexively questioning who I was in relation to the research, I was, indeed, taken to a site of resistance - my sexuality. Not until I had tried to make sense of how I might write reflectively about my work, did this aspect of who I was reveal itself, having been a lens; consciously or otherwise; I had not wanted to use. Once in view, it raised questions about my research practice - had I acted as a 'defended researcher' and been too invested in a particular way of reading the data (McLeod and Thomson, 2009, p. 75)? Had difficult feelings or experiences been 'heavily defended against at the level of the unconscious' (Lucey, Melody and Walkerdine, 2003, p. 282), causing me to think and act in otherwise unseen ways?

The concept of a 'defended' subject stems from psychoanalytical thinking and the idea that a dynamic unconscious defends against anxiety which, in doing so, can significantly influence the actions and lives of individuals (see Hollway and Jefferson, 2000). For my previous research, and the intimated invisibility of 'vulnerability' as a subject discussed within it, the potential implication was that there was something within me that had prevented the recognition of vulnerability as a more salient issue. Seeking solace and understanding, I found myself drawn to the following statement: 'We are psycho-social because the real events in the external, social world are desirously and defensively, as well as discursively, appropriated’ (Hollway, 2004, p. 7). 
As in social work practice, the interaction between a researcher's biographical history and the cultural setting is likely to hold emotional resonance for some topics and not others (McLeod and Thomson, 2009) and, similarly for social workers, it is important that researchers attempt to understand the implications of their own subjectivity, together with comprehending the power relations which surround them and which they, as individuals, are a part (Hollway, 2004). Thinking again about these relationships, I was reminded that it is the interaction between an individual's psychosocial worlds (the inner world of feelings and the outer world of external events, people and the physical environment) combined with an ability to move between the two, that is essential for both understanding and intervention (Schofield, 1998). Mindful of this, together with Schön’s (1983, p. 79) notion of ‘back-talk’ (feedback from a situation that shapes the subsequent response), I tried to be more systematic in terms of how I framed the relationship between my biographical characteristics, social work and the notion of vulnerability. As a result, what emerged were three questions, each becoming a reference point that served to marshal thinking and analysis:

1. Was there anything more in the data, related to vulnerability, that I had overlooked?

2. Had I made assumptions about vulnerability that had caused me to overlook something?

3. If either of the above rung true, what had caused this to be the case?

Using these as a guide, I sought new interpretations seated in a psychosocial approach, the intent being to increase the frames of experience (Fook, 2002) I had access to, along with the internalised discourses (Heron, 2005) that may have shaped them. 


\section{The power of vulnerability}

Anyone reading this article who has watched Brené Brown’s (2011) TED talk will already be familiar with the phrase used here. I consider myself committed to recognising and working with vulnerability in practice and Brown’s statement from a later book, naming vulnerability as 'the core, the heart, the centre, of meaningful human experiences' (2015, p. 12), resonates with me. It is also widely accepted, although has sometimes been forgotten (see Trevithick, 2014), that social work practice is emotional and can have a significant emotional impact on workers (Munro, 2011) and students (McSweeney, 2018). Furthermore, it is recognised that social workers (should) possess a relatively high level of emotional intelligence - the ability to distinguish between one's own emotions and those of others and to use this information to guide thinking and action (Morrison, 2007) - plus an ability to undertake emotional labour work necessitating the management of one's own emotions and the emotions of others (Moesby-Jensen and Nielsen, 2015; Winter et al, 2019); attributes that require practitioners to exercise ways of coping which may involve some sort of emotional containment (Ruch, 2007), or self-regulation (Trevithick, 2014).

Achieving this may entail balancing proximity to and distance from service users (MoesbyJensen and Nielsen, 2015) and managing emotional dissonance, from the use of humour to more defensive strategies where the worker may revert to bureaucratic approaches to practice (Winter et al, 2019). In trying to manage severely stressful situations, including experiences of direct and vicarious trauma, and retain some semblance of self-preservation, practitioners may also employ defences of denial and rationalisation (Goddard and Hunt, 2011). The effects of vicarious trauma, if unchecked, can lead to changes an individual's inner world, negatively impacting on beliefs about the self and the individual's world view, most notably in terms of cynicism and pessimism (Saakvitne, 2002). Fortunately, the value of exploring 
the emotional content of practice, for students (Grant, Kinman and Alexander, 2014; Karpetis, 2010; McSweeney, 2018) and practitioners (Ingram, 2015; Munro, 2011), has been generally recognised - something which underpinned the rationale for my previous study. In thinking about how the emotional demands of social work are readily accepted, I attempted to answer the first two of my questions: had I overlooked something in the data and had I made assumptions, in some way, about vulnerability? My first thoughts were that perhaps it was because vulnerability was so obviously a part of social work practice, I had not needed to attend specifically to it, but also, had I been ignorant to it, as I had not made it an initial focus of my study? If either phenomenon was the case, it represented a potential omission and prompted feelings - as apprehended by McLeod and Thomson (2009) in the re-visiting of their research - of discomfort. These thoughts represented the first steps I took towards locating myself back in the 'picture' of the research (see Fook, 1999), closely followed by a re-reading of what I had produced.

Vulnerability had been named in my original article and so I looked closer at how it had been framed: the term was present in respect of two themes - disclosure and permission (both evident in an overarching theme of 'discrete enabling actions taken by the Practice Educator'). In terms of the former, I had noted that self-disclosure, on the part of Practice Educators, could help show students that they were not exceptional, in the sense of feeling 'weak, unable to cope or silly' (Dore, 2019, p. 9) and could also show them that a range of emotional experiences were to be expected, as a reality of everyday practice. With regard to permission, I had viewed the ways Practice Educators created space for students to talk about their emotions, as a means of showing them that it was both a necessary and professional part of practice. Here, I realised that there were parallels between what I was researching and how I was doing it. In posing the question 'tell me about a time when supervision featured a 
discussion about a practice experience that was in some way emotive', I was essentially asking participants to make themselves vulnerable: the question invites a level of emotional exposure, where both sets of participants could have been taken back to a place involving uncertainty and risk - both salient elements of vulnerability (see Brown, 2015). With this connection explicit, I returned to the data to help answer the questions I had, this time with vulnerability as overt lens with which to frame interpretation and therefore the construction of material (see Fook, 2002).

Besides what I had included in the article, vulnerability was strongly evident in the feelings talked about in response to the interview questions. Feelings of stress, fear, agitation, anxiety, frustration, depression, anger and violation were all named in the interviews, with two participants (one student, one Practice Educator) making statements about it being 'ok' to be vulnerable. Yet, what I found more interesting was that, during two of the interviews, I had appeared discretely conscious of vulnerability as a topic:

\section{Excerpt 1:}

Michelle (Practice Educator) - 'Yes, vulnerability isn’t weakness'.

Researcher - 'Yeah, that's something I'm quite interested in'.

\section{Excerpt 2:}

Jess (student) - ' ... it's alright to be upset after something, it's not like a sign of weakness which is probably what I would kind of say, that, you know, crying is... yeah, usually I would say it's a bit of a sign of vulnerability or weakness, and actually it's alright to be vulnerable'

Researcher - 'Have you sat in any of my lectures?'. 
This stood out because, despite this apparent interest and presence of vulnerability in the data, I had not signposted it as an area for potential future research in its own right. What I had done was tack it to a suggestion that student characteristics be examined more closely relating it to findings that men more often fail social work training courses, perhaps owing to a reluctance to ask for help and ability to admit fault (Furness, 2012). While I had noted that these were 'two acts that could potentially prove emotive and provoke a strong sense of vulnerability’ (Dore, 2019, p. 13), I felt that, in some way, I had, indeed, been neglectful of vulnerability. More significantly, felt my critical gaze shift towards thinking about myself as a male researcher. From here, attention moved towards my third question, in essence, was there something related to being male that had caused me to talk about vulnerability in the way I had?

\section{Moving towards the biographical: developing reflexivity}

\section{Men in social work}

Over time, there has been much discussion about the disparity between the numbers of men and women entering social work (McLean, 2003; McPhail, 2004; Pease, 2011), perceptions of men as Social Workers (McPhail, 2004; Pease, 2011) and feelings men have about becoming social workers (Crabtree and Parker, 2014; Parker and Crabtree 2014; Labra, Chamblas, Turcotte and Dubé, 2018). Social work is very much a female majority profession (McPhail, 2004), an observation evident to anyone who has made a visit to a social services department, whether in the UK or further afield (Crabtree and Parker, 2014; Labra et al., 2018; Pease, 2011). In the UK, as at April 2019, women made up 82\% of those registered with the professional regulator, the Health and Care Professions Council, as a Social Worker 
(HCPC, 2019). While these figures are likely to include some academics, such as myself, and those undertaking other work which is not client facing, such as independent Practice Educators, this figure highlights a sustained disparity between the sexes, echoing previous findings (for example Parker and Crabtree, 2014). Figures for practitioners working on the front-line, in children and families social work teams, show a similar trend, with $85 \%$ being female (Department for Education, 2018).

The perception of social work as a female profession, or something that women do, is invariably bound up by persistent ideas of gender and gender roles, together with notions of what it means to be a man and masculinity. Conceptions of nurturing (McPhail, 2004) and caring (Parker and Crabtree, 2014), essential strands of practice, endure as roles felt to belong foremost to women - men in social work are greeted with ambivalence (Pease, 2011), being cast as 'hero', 'gentle man’ or viewed with suspicion and pathologised (Parker and Crabtree, 2014). These perceptions have served to perpetuate and reinforce the image of social work as being a profession for women, cementing the conditions where, as McLean asserts, 'assumptions about motivations, skills and abilities have ensured that social care work is usually carried out by women’ (2003, p. 45). In social work, the gendered expectations found in oppressive societal structures - typically tied to hegemonic masculinity - exert oppressive influence on both men and women, albeit in different ways. For men, the practitioner viewed as the 'gentle man' may be presumed to be gay (Parker and Crabtree, 2014) and male students seen as less able to reflect because 'women are more in-touch with their feelings' (Crabtree and Parker, 2014, p. 14). For women, men disproportionately occupy more management (Pease, 2011) or specialist (Parker and Crabtree, 2014) positions. As a potent force, masculinity, particularly hegemonic masculinity, shapes not just the spaces where social work is practised - the outer worlds of individuals - it also influences inner worlds, 
most visibly in terms of meaning and mood (see Schofield, 1998), but also in terms of identity and how this is expressed. This becomes more apparent when thinking about the subjugation and oppression experienced by subordinated groups, including gay men (see Parker and Crabtree, 2014), who may be less likely to be open about their sexuality at work, when employed in certain areas, such as children’s residential care (McLean, 2003). Thus, for those occupying any dominant subject position, the challenge is to critically assess one's position and the associated privileges that accompany it, as Pease puts it, 'developing a critical consciousness of oppression and privilege requires an interrogation of our own various identities and locations' (2011, p. 414). To do this, the inner world of feelings and ideas about the self and the world (Schofield, 1998) needs to become a thing of puzzlement.

\section{Becoming an unsettled self}

This may be an unsettling process, but also a positive one. Taken for granted ways of being, of positions in the world, may be called into question, as was the case for some of the male social work students in Parker and Crabtree’s study - as one participant demonstrates: 'It was challenging as a male and made me think about masculinity and maleness in a way I'd never thought about. It made me feel very pound. I also don’t see why I should shy away from telling people what I do’ (2014, p. 318). What many of the findings from these studies illustrates is the intertwined nature of social systems, where messages become self-replicating across different societal domains - predominantly those of family and economy. From the division of labour witnessed in the home (as related to emotional responsibility) being reflected in the work done by Social Workers (see Labra et al., 2018), to social work being viewed by some as low status, with little room to earn high wages (see Crabtree and Parker, 2014; Parker and Crabtree, 2014). These two systems themselves inter-related, most prominently when men are automatically viewed as being the 'provider'. In trying to gain a 
more sophisticated understanding of ways of being and of how things have come to be, a psychosocial approach is helpful, as it avoids a false dichotomy that might reduce the ability to see the hermeneutic circle that exists between society and the individual.

On this note, Sheppard and Charles' (2017) consideration of personality type is interesting, as it resonates with the subject of expectation seen in some of the other research. In particular, they reported a significant difference between males and females, with regard to scores across personality domains of anxiety, impulsivity and vulnerability, commenting that, for females (as the higher scorers), this would suggest women might face increased difficulties in coping with stress, than would men: in Parker and Crabtree's work, one of the male responders felt that, 'as a male', he should be able to handle stress better than his female counterparts (2014, p. 322). This example prompts the question, is the expectant educator falling prey to some kind of heuristically triggered response that shapes their expectations of what is likely to occur (Dore, 2018)? And what role have social discourses played in shaping the external expectations of others and (consequentially) the inner character of the subject, which then serves to reinforce those external expectations? Here the intertwined nature of the psychosocial appears indivisible, to the extent that 'the social and the unconscious might be said to be mutually constituted such that the one is always already present in the other' (Redman, 2005, p. 532). To think about processes of becoming is a prerequisite, an inherent position, of a psychosocial approach, and, to do so, one must consider the times and spaces that have led to the current self: as Schofield observes, it is the meaning that our inner world attributes to outer world events, over time, that can help make sense of the present (1998). In taking myself back to my research, thinking about who I was as a researcher, I readily engaged with my male identity, at ease with exploring thoughts about men as a minority in social work and the associated role of hegemonic structures. This was a conscious act. I had 
made a choice that I would exclude my sexual identity from being a biographical lens. In sum, I did not want to position myself as a male, gay, researcher. Yet, once surfaced, I became faced with a puzzling phenomenon to be understood (Schön, 1983). In relation to my third question, what had caused this to be the case? Why was I so resistant and what did it say about my own vulnerability?

\section{Widening the frame: messages of masculinity}

Levels of openness about sexuality in different social care roles (McLean, 2003); feelings that some parts of social work are no-go areas for men (Crabtree and Parker, 2014); and that men become 'purified and acceptable to the profession' through disassociating with that which is assumed to constitute 'men' (Parker and Crabtree, 2014, p. 22), were instrumental pieces of research which steered me towards gender expression and, subsequently, to sexuality, as a new reflective frame. Subsequently, I found myself taken back to the past and sought to gain a greater level of insight of my inner world, prepared to unlock the black-boxes (accepted understandings, usually immune from analysis) of the self, in order to permit a greater awareness of my unconscious. Essentially, I became open to undoing what I believed to know (see Redman, 2016), an increased awareness contributing to my on-going, 'wholeperson development' (Attia and Edge, 2017, p. 34). Getting to this point has been fuelled by an attraction to ideas of gender and sexuality as a performance. The earlier readings about men in social work, drawing me to the concept of hegemonic masculinity, with McLean's paper connecting with me, particularly the description of how women and marginalised men, including gay men, are able to attain positions of power and wealth by 'behaving in the required manner' (2003, p. 49). Later readings of Frosh et al (2003), Phoenix and Frosh (2001) and Redman (2005), served to broaden my interest in masculinity as a performance, its expression tied to desired projective traits and the avoidance of those seen as feminine, 
where the fear of homophobic insults, for young men, belie personal vulnerabilities. The performance of gender, from this perspective, is then a defensive strategy, enacted as a means to manage anxiety (Redman, 2005), where maintenance of a culturally located subject position (see Phoenix and Frosh, 2001) is wedded to embedded notions of power.

Drawing on Bruner’s ideas of ‘canonical narratives', that is 'general stories about how lives may be lived in the culture, serving to justify certain behaviours' (Frosh et al., 2003, p. 43; Phoenix and Frosh, 2001, p. 28), Phoenix and Frosh illustrate how boys can use these representations of masculinity to account for their interpretations of what represents popularity. Although 'negotiated' spaces were seen, where individuals could carve out nonhegemonic, but still masculine, identities, these were often servient to other stereotypical social discourses. Thinking about this further and the reciprocal relationship between external and inner worlds, I began to reflect on the messages of my youth, eloquently aided by narratives and interpretations presented by Frosh et al. (2003) - one boy’s account of having no interest in football being especially emotive. Touched by this, I felt myself taken back to secondary school, the smell of the school, the smell of the pitch. Consumed by a different time, a past world, my thoughts became attentive to 'ghosts of experience' (Bollas, 1994, p. 60) where I questioned my current self and that which surrounded me - the puzzlement experienced, befitting Bollas’ stance on wisdom being 'measured by increased uncertainty about the meaning of our self, or of life' (p. 61). Thoughts about what I had let be seen at different points in my life echoed from the past, leading me to consider the extent to which, consciously or otherwise, my identity had been policed by others and which of my identity positions had been, or were, the products of their external influence (see Frosh et al., 2003). In this space, I felt a greater level of self-awareness: the lights had been turned on in a darkened room, my position in that room a little clearer, if still uncertain. 


\section{Conclusion}

Using Schön’s reflexive scaffolding to advance a psychosocial understanding of myself as a researcher, I have explored biographical aspects of my identity in relation to my previous work. In doing so, insight has been gained in respect of how, if not why, personal experience has been - will continually be - 'mediated though the lens of [my] own body, biography and changing contexts' (Fook, 1999, p. 14). Adopting a psychosocial perspective has enabled me to think more deeply about the role played by possible unconscious processes and the interaction between inner and outer worlds, as related to research. Holding parallels with social work practice, it can be seen that this kind of analysis has much to offer in terms of broadening an understanding of knowledge production more generally - something beyond the scope of this article to explore further, but to perhaps revisit in future research.

Any level of (self-) reflection will be limited to what one has access to, therefore striving for a holistic experience, calls for efforts to maximise the range of perspectives available (Fook, 2002). Engaging in this reflective process raised a number of questions, personal and professional, and despite the lack of confident answers, I have been unsettled as a researcher. As such, I feel more alert to the ways 'I' might shape the way I view, construct and obtain knowledge (Fook, 1999) - now more conscious of the lenses through which I choose (or do not choose) to see. Perhaps, akin to Richards (2015), I too have experienced 'epiphanies' through the revisiting of past-selves, in past worlds.

\section{References}


Attia, M. and Julian, E. (2017). Be(com)ing a reflexive researcher: a developmental approach to research methodology. Open Review of Educational Research, 4, 1, 33-45.

Banks, S. (2016). Everyday Ethics in Professional Life: Social Work as Ethics Work. Ethics and Social Welfare 10, 1, 35-52.

Bollas, C. (1994). Being a Character: Psychoanalysis and Self Experience. New York: Hill and Wang.

Brown, B. (2011). The power of vulnerability. TEDxHuston: recorded lecture. Available at: https://www.ted.com/talks/brene_brown_on_vulnerability?language=en

Brown, B. (2015). Daring Greatly. London: Penguin Random House.

Crabtree, S. and Parker, J. (2014). Being Male in Female Spaces: Perceptions of Masculinity Amongst Male Social Work Students on a Qualifying Course. Revista de Asistenţă Socială, XIII, 4, 7-26.

Department for Education (2018). Experimental statistics: Children and family social work workforce in England, year ending 30 September 2017. Retrieved from: https://assets.publishing.service.gov.uk/government/uploads/system/uploads/attachment_data /file/681546/SFR09-2018_Main_Text.pdf

Dore, I. (2018). Social work on the edge: not knowing, singularity and acceptance. European Journal of Social Work, 1-12. doi: 10.1080/13691457.2018.1463971 
Dore, I. (2019). Talking about emotion: how are conversations about emotion enabled in the context of social work practice education? Social Work Education, 1-15. doi: $\underline{10.1080 / 02615479.2019 .1591361}$

Ellis, C., Adams, T. and Boucher, A. (2011). Autoethnography: An Overview. Forum: Qualitative Social Research, 12, 1. Retrieved from: http://nbn-resolving.de/urn:nbn:de:0114$\underline{\text { fqs1101108 }}$

Fook, J. (1999). Reflexivity as Method. Annual Review of Health Social Sciences, 9, 1, 11-20.

Fook, J. (2002). Theorizing from Practice. Qualitative Social Work, 1 (1), 79-95.

Frosh, S., Phoenix, A. and Pattman, R. (2003). Taking a stand: Using psychoanalysis to explore the positioning of subject in discourse. The British Journal of Social Psychology, 42, 39-53.

Furness, S. (2012). Gender at work: Characteristics of ‘failing’ social work students. British Journal of Social Work, 42, 480-499.

Goddard, C. and Hunt, S. (2011). The complexities of caring for child protection workers: the contexts of practice and supervision. Journal of Social Work Practice, 25, 4, 413-432. 
Grant, L., Kinman, G., \& Alexander, K. (2014). What's all this talk about emotion?

Developing emotional intelligence in social work students. Social Work Education, 33, 7, 874-889.

Gray, M., and Webb, S. A. (2013). Introduction. In M. Gray and S. A. Webb (Eds.), Social work theories and methods. Second Edition. 1-10. London: Sage.

HCPC (2019). Registrants by profession and route and gender. Retrieved from:

https://www.hcpc-uk.org/globalassets/resources/data/2019/registrant-snapshot---april-

2019.pdf

Heron, B. (2005). Self-reflection in critical social work practice: subjectivity and the possibilities of resistance. Reflective Practice, 6, 3, 341-351.

Hollway, W. (2004). Psycho-Social Research Editorial. International Journal of Critical Psychology, 10. 5-12. London: Lawrence and Wishart.

Hollway, W. and Jefferson, T. (2000). Doing Qualitative Research Differently. London: Sage.

Ingram, R. (2015). Exploring emotions within formal and informal forums: Messages from social work practitioners. British Journal of Social Work, 45, 896-913. 
Karpetis, G. (2010). Field practice supervision of social work students: a psychodynamic view on the emotional context of the process and the setting during the client assessment phase. European Journal of Social Work, 13, 4, 503-522.

Labra, O., Chamblas, I,. Turcotte, P. and Dubé, N. (2018). Is It a Man’s World? An Exploratory Study of Male Students in Social Work: Experiences from Chile. British Journal of Social Work, 48, 769-786.

Leonard, K. and O’Connor, L. (2018). Transitioning from 'outside observer' to 'inside player' in social work: practitioner and student perspectives on developing expertise in decision-making. Journal of Social Work Practice, 32, 2, 205-218.

Lucey, H., Melody, J. and Walkerdine, V. (2003). Project 4:21 Transitions to Womanhood: Developing a psychosocial perspective in one longitudinal study. International Journal of Social Research Methodology, 6, 3, 279-284.

McLean, J. (2003). Men as Minority. Men Employed in Statutory Social Care Work. Journal of Social Work, 3, 1, 45-68.

McLeod, J. and Thomson, R. (2009). Researching Social Change. Qualitative Approaches. London: Sage.

McPhail, B. (2004). Setting the Record Straight: Social Work Is Not a Female-Dominated Profession. Social Work, 49, 2, 323-326. 
McSweeney, F. (2018). Themes in the supervision of social care students in Ireland: building resilience. European Journal of Social Work, 21,3, 374-388.

Moesby-Jensen, C. and Nielsen, H. (2015). Emotional labor in social worker's practice. European Journal of Social Work, 18, 5, 690-702.

Morrison, T. (2007). Emotional Intelligence, Emotion and Social Work: Context, Characteristics, Complications and Contribution. British Journal of Social Work, 37, 245263.

Munro, E. (2011). The Munro review of child protection: Final report - A child-centred system. Retrieved from:

https://www.gov.uk/government/uploads/system/uploads/attachment_data/file/175391/Munro -Review.pdf

Parker, J. and Crabree, S. (2014). Fish Need Bicycles: An Exploration of the Perceptions of Male Social Work Students on a Qualifying Course. British Journal of Social Work, 44, 310327.

Pease, B. (2011). Men is Social Work: Challenging or Reproducing an Unequal Gender Regime? Journal of Women and Social Work, 26, 4, 406-418.

Phoenix, A. and Frosh, S. (2001). Positioned by “'Hegemonic”' Masculinities: A Study of London Boys’ Narratives of Identity. Australian Psychologist, 36, 1, 27-35. 
Redman, P. (2005). Who cares about the psycho-social? Masculinities, schooling and the unconscious. Gender and Education, 17, 5, 531-538.

Redman, P. (2016). Once more with feeling: What is the psychosocial anyway? Journal of Psycho-Social Studies, 9, 1, 73-93. Retrieved from: http://www.psychosocial-studiesassociation.org/wp-content/uploads/2017/01/Peter-Redman-Once-More-With-Feeling.pdf

Richards, M. (2015). Turning back to the story of my life: an autoethnographic exploration of a researcher's identity during the PhD process. Reflective Practice, 16, 6, 821-835.

Ruch, G. (2000). Self and social work: towards an integrated model of learning. Journal of Social Work Practice, 14, 2, 99-112.

Ruch, G. (2007). 'Knowing’, Mirroring and Containing: Experiences of Facilitating Child Observation Seminars on a Post-Qualification Child Care Programme. Social Work Education, 26, 2, 169-184.

Saakvitne, K. (2002). Shared Trauma: The Therapist’s Increased Vulnerability. Psychoanalytic Dialogues, 12, 3, 443-449.

Schofield, G. (1998). Inner and outer worlds: A psychosocial framework for child and family social work. Child and Family Social Work, 3, 1, 57-67.

Schön, D. (1983). The Reflective Practitioner: how professionals think in action, New York: Basic Books. 
Sheppard, M. and Charles, M. (2017). Personality in those entering social work training in England: comparing women and men. European Journal of Social Work, 20, 2, 288-296.

Trevithick, P. (2014). Humanising Managerialism: Reclaiming Emotional Reasoning, Intuition, the Relationship, and Knowledge and Skills in Social Work. Journal of Social Work Practice, 28, 3, 287-311.

Winter. K., Morrison, F., Cree, V., Ruch, G., Hadfield, M. and Hallett, S. (2019). Emotional Labour in Social Workers' Encounters with Children and Their Families. British Journal of Social Work, 49, 217-233. 